\title{
Scanning Tunneling Mlcroscopy and Scanning Electron Microscopy Observations of the Early Stage of Silver Deposition on Graphlte Single Crystal Electrodes
}

\author{
L. Vázquez, ${ }^{\dagger}$ A. Hernåndez Creus, ${ }^{\ddagger}$ P. Carro, ${ }^{\ddagger}$ P. Ocón, ${ }^{\S}$ P. Herrasti, ${ }^{\S}$ C. Palacio, ${ }^{\dagger}$ J. M. Vara, ${ }^{\S}$ \\ R. C. Salvarezza, and A. J. Arvia*,\|
}

\begin{abstract}
Departamento de Fisica Aplicada C-XII, Consejo Superior de Investigaciones Cientificas, Instituto de Ciencia de Materiales, sede B, Universidad Autónoma de Madrid, 28049 Madrid, Spain, Departamento de Quimica-Fisica, Universidad de La Laguna, La Laguna, Tenerife, Spain, Departamento de Quimica-Fisica Aplicada C-II, Universidad Autónoma de Madrid, 28049 Madrid, Spain, Instituto de Investigaciones Fisicoquimicas Teóricas y Aplicadas (INIFTA), Casilla de Correo 16. Sucursal 4, 1900 La Plata, Argentina (Received: May 14, 1992; In Final Form: August 19, 1992)
\end{abstract}

\begin{abstract}
The early stages of $\mathrm{Ag}$ overpotential deposition on highly oriented pyrolytic graphite (HOPG) from $\mathrm{Ag}^{+}$-ion-containing acid solutions have been studied by ex situ scanning tunneling microscopy and scanning electron microscopy imaging complemented with electrochemical, energy dispersive X-ray analysis, and Auger electron spectroscopy data. Nucleation and 3D Ag growth initiate at surface defects. Unstructured 3D Ag nuclei decorating HOPG steps and flat geometric Ag islands are formed around the steps. The island structure is compatible with a local layer-by-layer growth. The entire morphology of the $\mathrm{Ag}$ deposit is consistent with a growth mechanism involving $\mathrm{Ag}$ atom diffusion from 3D nuclei at step edges toward $\mathrm{Ag}$ flat domains. Images with atomic resolution reveal large uncovered HOPG areas and Ag submonolayer domains with the nearest-neighbor distance $d=0.33 \pm 0.02 \mathrm{~nm}$, whereas flat $\mathrm{Ag}$ islands exhibit $d=0.29 \pm 0.02 \mathrm{~nm}$ as expected for the nearest-neighbor distance in the $\mathrm{Ag}$ lattice. A model for these structures is discussed.
\end{abstract}

\section{Introduction}

The interest in the very early stages of metal electrodeposition both in the underpotential (upd) and overpotential (opd) regions encourages further investigations to demonstrate the validity of growth models and phase transitions operating at different stages of the process. ${ }^{1}$ The rapid development in the application of scanning tunneling microscopy (STM) to electrochemical systems involving well-defined substrates under different operating conditions allows the examination of growth processes from the early formation of a single monolayer to deposition equivalent to several atomic layers.

Despite the fact that there are still no universally accepted criteria concerning the optimum STM operating mode in electrochemistry, a number of very interesting results and conclusions concerning the electrocrystallization of metals have been reported in recent years. ${ }^{2-8}$ Investigations of the upd of metals with atomic resolution ${ }^{3-6}$ and the early stages of $\mathrm{Cu}$ opd on Au single-crystal electrodes have been made using STM.

For upd of metals, ordered overlayers have been reported from STM and AFM imaging. ${ }^{3-6}$ These overlayers exhibit open structures with packaging densities which depend on the anion present in the electrolyte solution. A partial charge transfer from anions to metal adatoms has been proposed to explain the experimental results. It should be noted that due to the difference in electronegativities between substrate and metal adatoms, the latter remains with a small positive charge. ${ }^{5}$

STM observations indicate that the initial opd of metals occurs at step edges, dislocations, and defects in the substrate surface. Subsequently, the deposition of metals takes place on flat substrate terraces, the rate of growth of the deposit being far faster in the $x$ - and $y$-directions than it is in the $z$-direction. ${ }^{7}$ For $\mathrm{Cu}$ electrodeposition on $\mathrm{Pt}$, it has been concluded that a 2D layer-by-layer growth mechanism does not account for the process, although in this case the shape of $\mathrm{Cu}$ crystallites is not well-defined at the carly stages of growth, it changes into a better defined morphology at later stages.

\footnotetext{
'Departamento de Física Aplicada C-XII, Universidad Autónoma de Madrid.

IDepartamento de Quimica-Física, Universidad de La Laguna.

- Departamento de Ouimica-Física Aplicada C-II, Universidad Autónoma de Madrid.

INIFTA
}

The opd of Ag on graphite surfaces has also been studied from in situ STM. ${ }^{8-10}$ At the rest potential, the STM images revealed large features attributed to Ag electrodeposits and relatively large uncovered domains of graphite even for $\mathrm{Ag}$ electrodeposits equivalent to about $300 \mathrm{Ag}$ monolayers. ${ }^{8}$ Therefore, only unstructured 3D Ag deposits were observed from in situ STM imaging of opd $\mathrm{Ag}$ under potentiostatic control., ${ }^{9,10}$ These results were interpreted through a pure island rather than a combined island-and-layer growth mechanism.

The present work refers to the early stage of Ag electodeposition from $\mathrm{Ag}^{+}$-ion-containing acid solutions on highly oriented pyrolytic graphite (HOPG) followed by ex situ STM and SEM imaging complemented with EDAX, AES, and additional data derived from electrochemical measurements. The ex situ STM technique was used to avoid any modification of the local potential and diffusion fields at the working electrode surface which can be induced by the tip for in situ operations. ${ }^{7}$ These effects could produce important changes in the growth mode of the Ag deposit.

For the first time structures of Ag deposits from the submonolayer level to large geometric crystals of thicknesses equivalent to several monolayers are observed. The Ag submonolayer domains exhibit an open structure with nearest-neighbor distances $d=0.33 \pm 0.02 \mathrm{~nm}$, i.e., a value of $d$ larger than that corresponding to the nearest-neighbor distance in the $\mathrm{Ag}$ lattice. $\mathrm{A}$ mechanism involving nucleation and 3D growth at substrate steps followed by surface diffusion of atoms from these nuclei inward to form flat domains is presented. In this way the Ag coverage of the HOPG substrate can be explained through the formation of flat terraces which behave as precursors of Ag crystal faces.

\section{Experimental Section}

The Ag electrodeposition on HOPG from acid solutions was studied by using conventional electrochemical techniques combined with SEM, EDAX, AES, and STM.

Current-potential profiles related to the Ag electrodeposition/anodic stripping on HOPG were obtained in a conventional electrochemical cell with a HOPG working electrode, a $\mathrm{Pt}$ polycrystalline counterelectrode, and a $\mathrm{Hg} / \mathrm{Hg}_{2} \mathrm{SO}_{4}$ electrode (MSE) as reference; $E_{\mathrm{r}}\left(\mathrm{Hg} / \mathrm{Hg}_{2} \mathrm{SO}_{4}\right)=0.615 \mathrm{~V}$ vs normal hydrogen electrode. Potentials in the text are given in the MSE scale. Each current-potential curve was run with a freshly exfoliated HOPG surface immersed in $5 \times 10^{-3} \mathrm{M} \mathrm{Ag}_{2} \mathrm{SO}_{4}+10^{-2} \mathrm{M} \mathrm{H}_{2} \mathrm{SO}_{4}+0.5$ $\mathrm{M} \mathrm{Na}_{2} \mathrm{SO}_{4}$ solution at $0.02 \mathrm{~V} \mathrm{~s}^{-1}$ between $0 \mathrm{~V}$ and $-0.480 \mathrm{~V}$. The 


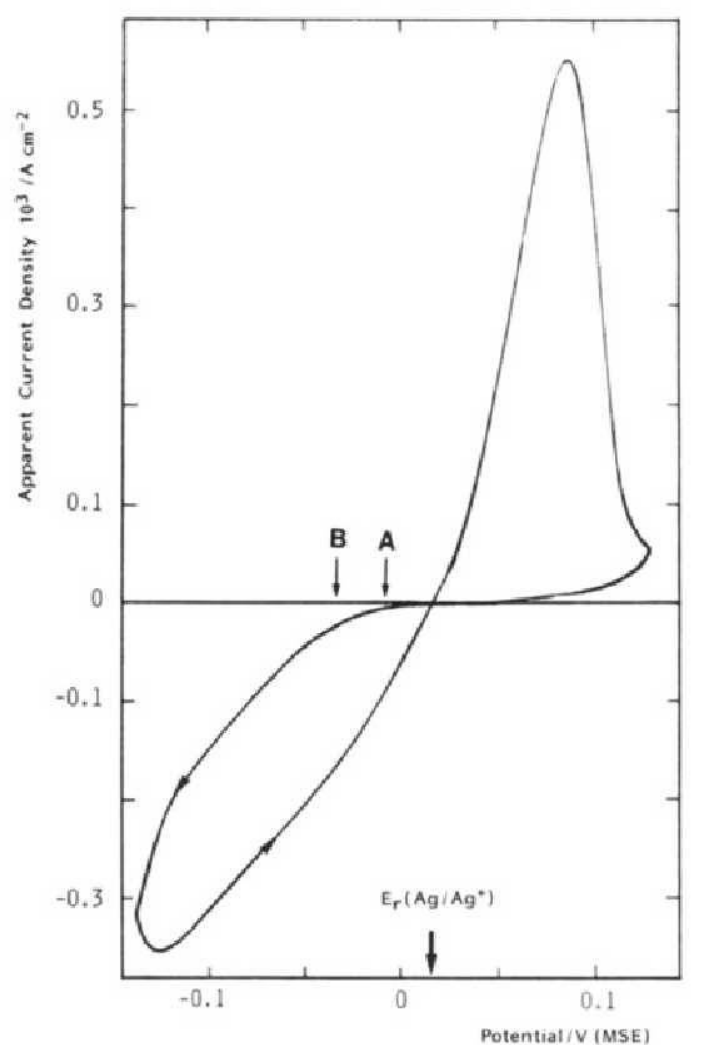

Figure 1. Current-potential profile recorded at $0.02 \mathrm{~V} / \mathrm{s}$ for HOPG in $5 \times 10^{-3} \mathrm{M} \mathrm{Ag}_{2} \mathrm{SO}_{4}+0.5 \mathrm{M} \mathrm{Na}_{2} \mathrm{SO}_{4}+10^{-2} \mathrm{M} \mathrm{H}_{2} \mathrm{SO}_{4}, 25^{\circ} \mathrm{C}$.

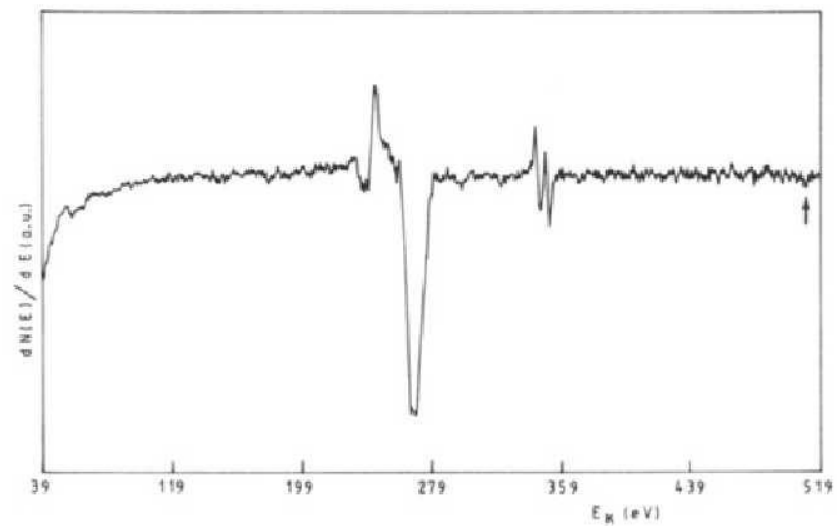

Figure 2. AES spectrum obtained for a $\mathrm{Ag}$ electrodeposit grown on HOPG after $6 \mathrm{~h}$ of exposure to the atmosphere.

composition of the solution was selected on the basis of previous data related to the $\mathrm{Ag}$ opd on a polyfaceted $\mathrm{Pt}$ single crystal sphere. ${ }^{11}$ The solutions were prepared with A.R. chemicals and were deaerated by bubbling purified $\mathrm{N}_{2}$ prior to the electrochemical runs.

For SEM and STM imaging the Ag electrodeposition was made at a constant cathodic overpotential in the $-0.05 \mathrm{~V} \leq \eta_{\mathrm{c}} \leq 0 \mathrm{~V}$ range; $\eta_{\mathrm{c}}=E-E_{\mathrm{r}}\left(\mathrm{Ag} / \mathrm{Ag}^{+}\right)$, where $E$ is the applied electric potential and $E_{\mathrm{r}}\left(\mathrm{Ag} / \mathrm{Ag}^{+}\right)=0.015 \mathrm{~V}$ is the reversible potential of the $\mathrm{Ag} / \mathrm{Ag}^{+}\left(10^{-2} \mathrm{M}\right)$ after ionic strength correction. The apparent charge density related to the Ag electrodeposits was in the $1-2 \mathrm{mC} \mathrm{cm}-2$ range, and the electrodeposition time was varied between 10 and $30 \mathrm{~s}$. These results were checked through the anodic stripping voltammogram of each $\mathrm{Ag}$ electrodeposit run after the corresponding STM imaging.

The Ag deposit topography was studied in the micrometer and the nanometer range by using SEM complemented by EDAX and ex situ STM, respectively. SEM and STM imaging were made after removing the working electrode from the electrochemical cell, rinsing in water by successive smooth immersions, and finally drying under $\mathrm{N}_{2}$ at room temperature.
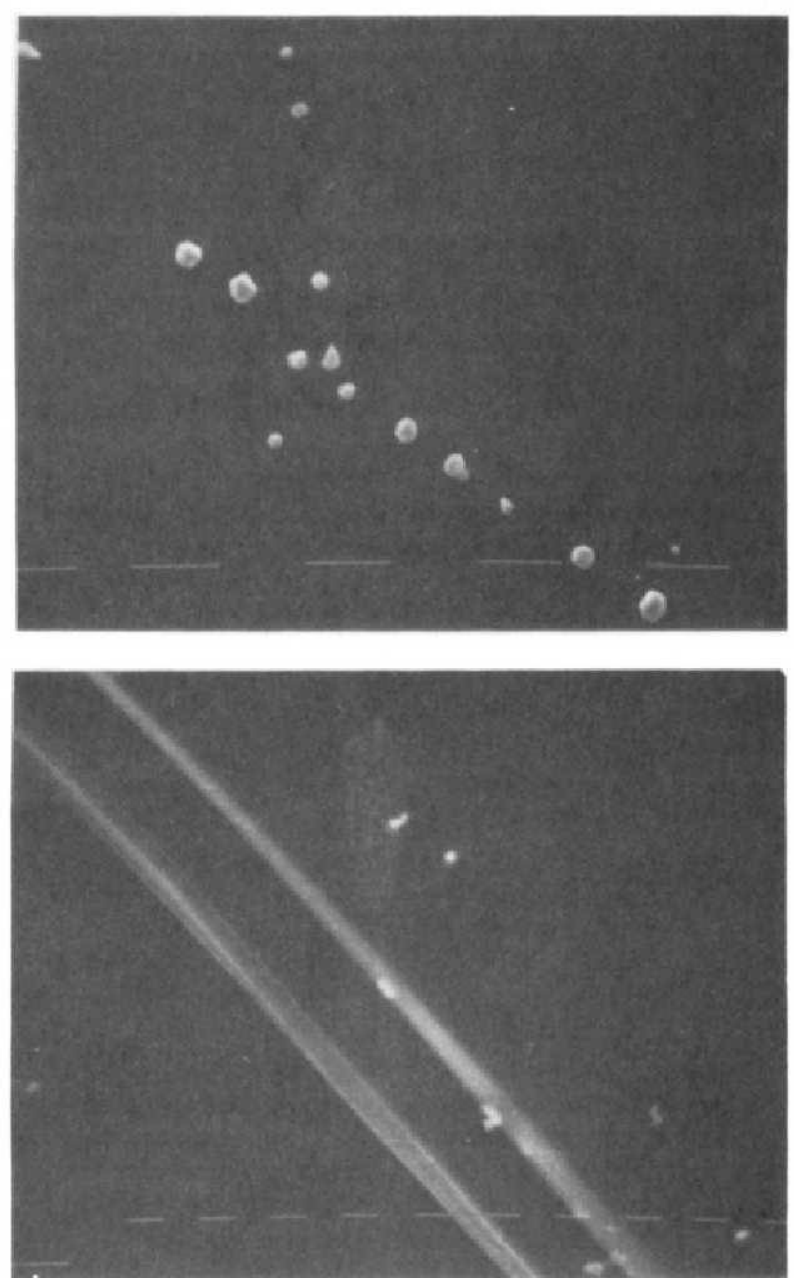

Figure 3, SEM micrographs of $\mathrm{Ag}$ electrodeposits on HOPG at $\eta_{\mathrm{c}}=$ $-0.025 \mathrm{~V}$; (a, top) $q_{\mathrm{c}}=2 \mathrm{mC} \mathrm{cm}^{-2}$, (b, bottom), $q_{\mathrm{c}}=1 \mathrm{mC} \mathrm{cm}^{-2}$. The horizontal bars indicate (a) $10 \mu \mathrm{m}$ and (b) $1 \mu \mathrm{m}$.

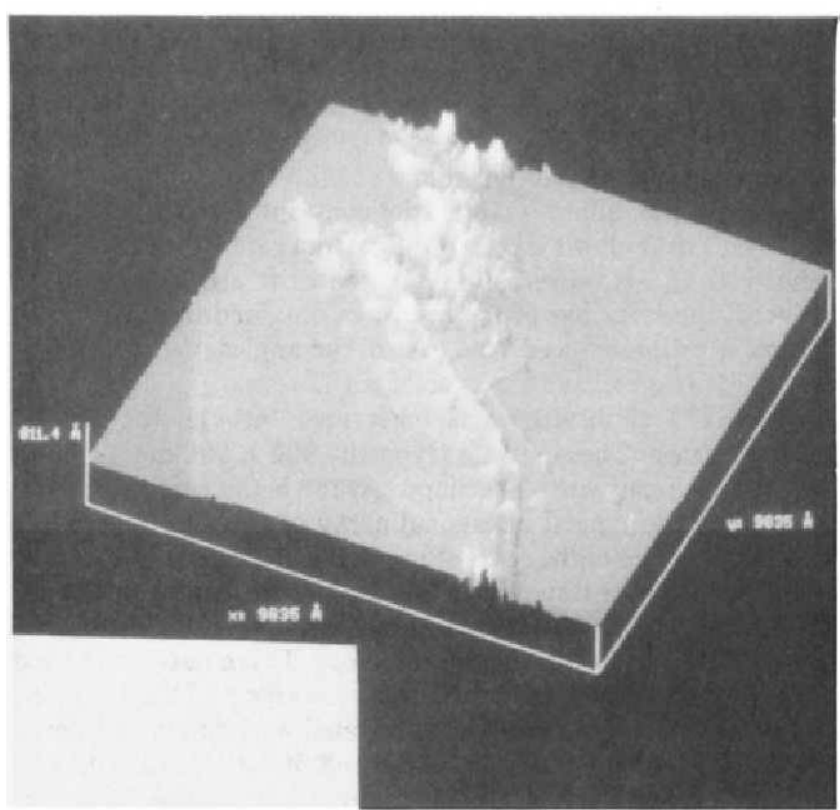

Figure 4. 3D STM image $\left(983 \times 983 \mathrm{~nm}^{2}\right)$ of HOPG after Ag electrodeposition at $\eta_{\mathrm{c}}=-0.025 \mathrm{~V}, q_{\mathrm{c}}=1 \mathrm{mC} \mathrm{cm} \mathrm{m}^{-2}$. Total height difference, $\Delta h=81.2 \mathrm{~nm}$.

The STM images were obtained within the first $6 \mathrm{~h}$ after the sample removal from the cell by using a piezo-tube STM operating in air. The interference of possible contamination of samples coming from the atmosphere during ex situ STM imaging was tested using Auger spectroscopy analysis (AES). 

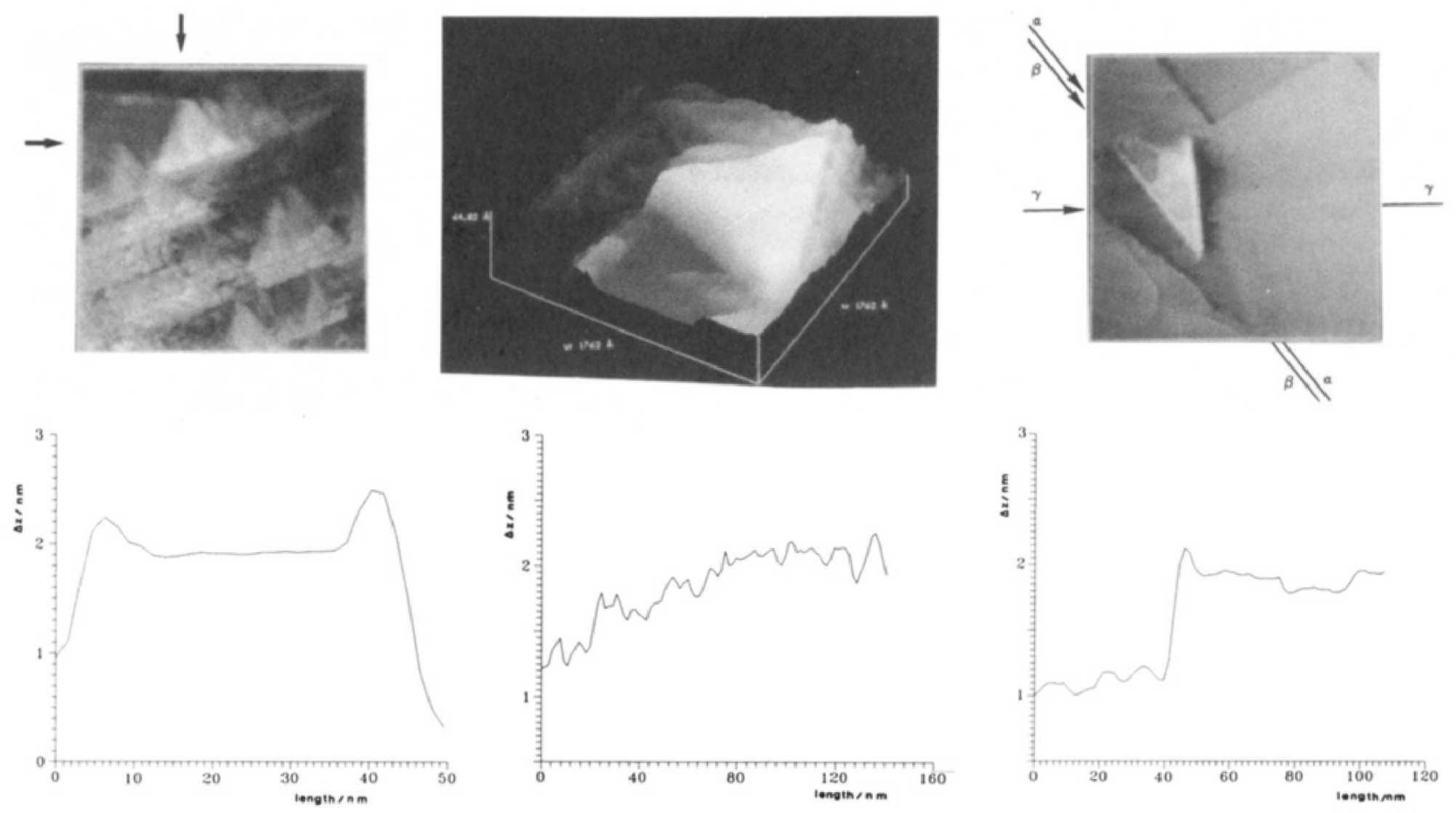

Figure 5. STM images of HOPG after Ag electrodeposition at $\eta_{\mathrm{c}}=-0.025 \mathrm{~V}$ and $q_{\mathrm{c}}=1 \mathrm{mC} \mathrm{cm}^{-2}$; (a, top left) $410 \times 410 \mathrm{~nm}^{2}$ (top view), $\Delta h=8.8$ $\mathrm{nm}$; (b, top middle) $176 \times 176 \mathrm{~nm}^{2}$ (3D), $\Delta h=6.5 \mathrm{~nm}$; (c, top right) $300 \times 300 \mathrm{~nm}^{2}$ (top view), $\Delta h=3.1 \mathrm{~nm}$; (d-f, bottom, left to right) cuts of the triangular Ag crystallite shown in Figure $5 \mathrm{c}$ following the directions $\alpha, \beta$, and $\gamma$, respectively.

AES analysis was carried out in an ultrahigh vacuum chamber at a base pressure better than $10^{-9}$ Torr using a cylindrical mirror analyzer (CMA) with a resolution of $0.25 \%$. A modulation voltage of $1 \mathrm{~V}_{\mathrm{pp}}$ was applied to the CMA. A constant primary electron beam current of $0.5 \mu \mathrm{A}$ at $3 \mathrm{kV}$ was used.

The platinum tips used for STM imaging were made by cutting $0.5 \mathrm{~mm}$ diameter $\mathrm{Pt}$ wires. The images were obtained by applying a $0.05-\mathrm{V}$ bias voltage with the tip positive at $1-2 \mathrm{nA}$ constant current. The precision of the STM distances measured at the atomic scale is usually affected by two main causes: the hysteresis and the thermal drift of the piezoelectric tube. We have used different experimental ways to minimize drift effects. Thus, atomic distances were measured along the $x$-axis where the atomic corrugation is imaged faster at ca. $0.05 \mathrm{~s} \mathrm{scan}^{-1}$. In addition, the current mode was used for atomic resolution imaging (for conventional topographic imaging the constant current mode was employed) as it allows the use of high scan rates (total collection time $\approx 10 \mathrm{~s}$ ). However, although the drift effects have been reduced, the error bar of the distances obtained from the STM images is estimated as $\pm 10 \%$. Also, the angles measured from the STM images have an error of $\pm 10 \%$.

The STM calibration was performed through the HOPG surface lattice. These images (typically $900 \times 900 \mathrm{~nm}^{2}$ ) exhibit flat surface areas with some steps. At the highest resolution (40 $\times 40 \mathrm{~nm}^{2}$ ) the typical hexagonal array of $\mathrm{C}$ atoms where one images only three of the six $\mathrm{C}$ atoms in the graphite lattice leading to nearest-neighbor distances of $0.24 \pm 0.02 \mathrm{~nm}$ can be observed. ${ }^{12}$ In addition, the honeycomb structure with the $\mathrm{C}-\mathrm{C}$ distance of $0.14 \pm 0.02 \mathrm{~nm}$ has been also resolved. These data were used to confirm the $10 \%$ error bar in the measurement of the distances.

Data were acquired in a fully automated workstation and stored as digitized images with $200 \times 200$ or $400 \times 400$ pixels. The scan rate was $300 \mathrm{~nm} \mathrm{~s}^{-1}$. The atomic distances given in this work have been obtained from raw data images, although they are shown slightly filtered in the corresponding figures.

\section{Results and Interpretation}

3.1. Electrochemical Data. The cyclovoltammograms corresponding to the Ag electrodeposition/electrodissolution on HOPG were recorded at $0.02 \mathrm{~V} \mathrm{~s}^{-1}$ in $5 \times 10^{-3} \mathrm{M} \mathrm{Ag}_{2} \mathrm{SO}_{4}+0.5 \mathrm{M}$ $\mathrm{Na}_{2} \mathrm{SO}_{4}+10^{-2} \mathrm{M} \mathrm{H}_{2} \mathrm{SO}_{4}$ (Figure 1) by setting the anodic switching potential as low as possible to avoid the HOPG substrate electrooxidation. The voltammogram shows a cathodic current which initiates at a few millivolts below $E_{\mathrm{r}}\left(\mathrm{Ag} / \mathrm{Ag}^{+}\right)$and extends down to the cathodic switching potential value. The reverse scan exhibits a hysteresis loop involving a cathodic current greater than that recorded in the preceding negative potential going scan. This loop is related to the nucleation and $3 \mathrm{D}$ growth of $\mathrm{Ag}$ on HOPG. ${ }^{1.11}$ As the potential scan exceeds $E_{\mathrm{r}}\left(\mathrm{Ag} / \mathrm{Ag}^{+}\right)$, an anodic current peak at $0.075 \mathrm{~V}$ which is related to the stripping of the Ag electrodeposit can be observed.

The arrows labeled $\mathrm{A}\left(\eta_{\mathrm{c}}=0.025 \mathrm{~V}\right)$ and $\mathrm{B}\left(\eta_{\mathrm{c}}=0.05 \mathrm{~V}\right)$ in the voltammogram indicate the potentials at which the Ag electrodeposits were grown for ex situ SEM and STM imaging.

3.2. AES Results. The Auger spectrum of Ag electrodeposits grown on HOPG by the procedure described above after $6 \mathrm{~h}$ exposure to the atmosphere (Figure 2) is characterized by three peaks at 271,350 , and $356 \mathrm{eV}$. The peak at $271 \mathrm{eV}$ is assigned to $\mathrm{KL}_{23} \mathrm{~L}_{23}$ Auger transition of $\mathrm{C}$ and presents the typical graphitic shape. The peaks at 350 and $356 \mathrm{eV}$ are due to the characteristic $\mathrm{M}_{45} \mathrm{~N}_{45} \mathrm{~N}_{45}$ doublet of $\mathrm{Ag}$, the separation being that between $\mathrm{M}_{4}$ and $M_{5}$ levels. Although AES is not extremely sensitive to oxygen, no reliable oxygen feature can be detected in the noise of the spectrum near $500 \mathrm{eV}$. Even assuming that this noise corresponds to the oxygen peak (arrow in the spectrum), the oxygen coverage should be $\leq^{1} / 3$ monolayer. Besides, the fact that no shift in the $\mathrm{M}_{5} \mathrm{~N}_{45} \mathrm{~N}_{45}$ and $\mathrm{M}_{4} \mathrm{~N}_{45} \mathrm{~N}_{45}$ transitions can be observed confirms that practically no oxide is present on the $\mathrm{Ag}$ surface.

3.3. SEM Imaging. SEM images of opd Ag electrodeposits produced at $\eta_{\mathrm{c}}=-0.025 \mathrm{~V}$ (arrow A, Figure 1) for an apparent charge density (charge/HOPG geometric area) $q_{\mathrm{c}} \simeq 2 \mathrm{mC} \mathrm{cm}^{-2}$ (Figure $3 \mathrm{a}$ ), show flat HOPG domains with isolated geometric $\mathrm{Ag}$ crystals which are aligned in well-defined directions. The latter are compatible with the possible directions of HOPG steps. By reduction of the charge to $q_{\mathrm{c}} \simeq 1 \mathrm{mC} \mathrm{cm}^{-2}$, small agglomerates (bright spots in the micrograph) which are associated with substrate irregularities can be observed (Figure 3b). These agglomerates are $\mathrm{Ag}$ deposits, as revealed by EDAX.

3.4. STM Imaging. The STM images $\left(983 \times 983 \mathrm{~nm}^{2}\right)$ of a Ag electrodeposit (Figure 4), which was prepared as described above in section 3.3 (Figure $3 \mathrm{~b}$ ), show Ag agglomerates surrounding HOPG steps. These patterns result from nucleation and growth phenomena at solid substrate defects as it has been already 
reported for the growth of new phases at solid/gas ${ }^{13}$ and solid/ electrolyte ${ }^{7}$ interfaces.

In principle, the $\mathrm{Ag}$ deposits exhibit two distinguishable morphologies, namely, unstructured 3D grains and geometric crystallites with well-defined angles. The latter show up a flat morphology often surrounded by a certain number of small 3D Ag nuclei (Figure 5a). The root mean square (rms) roughness resulting for the overall image is close to $1.3 \mathrm{~nm}$. The 3D nuclei $0.6 \mathrm{~nm}$ height and $20 \mathrm{~nm}$ diameter average dimensions are preferentially aligned very likely following the HOPG step directions. It should be noted that fine structured steps with a periodicity ranging from 2 to $8 \mathrm{~nm}$ size have been observed on HOPG without deposit. ${ }^{14}$ These figures are certainly much smaller than the $20-\mathrm{nm}$ distance between contacting $3 \mathrm{D}$ nuclei, so that the $3 \mathrm{D}$ nuclei patterns can be described as that of $\mathrm{Ag}$ decorated HOPG steps.

The $\mathrm{Ag}$ deposit also exhibits triangular $\mathrm{Ag}$ crystallites with flat terraces $(0.3 \mathrm{~nm} \mathrm{rms})$ involving 3D Ag nuclei at $\mathrm{Ag}$ terrace edges following the same preferred direction (Figure 5a). The STM images demonstrate that at $\mathrm{Ag}$ crystal edges the degree of disorder becomes relatively larger than at $\mathrm{Ag}$ terrace domains. Thus, the height of 3D nuclei formed at the edge of Ag crystallites (Figure $5 \mathrm{a}$, top left, see arrows) exceeds the height at the central part of the $\mathrm{Ag}$ terrace (rms $<0.3 \mathrm{~nm}$ ) (Figure $5 \mathrm{~b}$ ). The picture also shows a number of $\mathrm{Ag}$ crystals resulting from the overlapping of several growing $\mathrm{Ag}$ subterraces of different heights. This $\mathrm{Ag}$ growth pattern is comparable to that recently reported for opd $\mathrm{Pb}$ terraces grown on $\mathrm{Ag}^{15}$ The angles formed by the intersecting $\mathrm{Ag}$ terraces are $60 \pm 10^{\circ}$ and $30 \pm 10^{\circ}$ for the highest and the lowest terraces, respectively. Likewise, isolated Ag crystals are usually found surrounding $\mathrm{Ag}$ agglomerates.

A more detailed inspection of the Ag crystals (Figure 5c) provides valuable information about the likely $\mathrm{Ag}$ growth mechanism. Thus, the edges of the partially developed Ag triangularly-shaped crystal shown in Figure 5c determine a $30 \pm$ $10^{\circ}$ angle, but the right-hand-side (rhs) crystal edge becomes higher $(0.3 \mathrm{~nm})$ than the left-hand-side (lhs) Ag crystal edge (0.3 $\mathrm{nm}$ ) (Figure 5d). The latter is constituted by parallel steps which are decorated by small $\mathrm{Ag}$ nuclei of about $10 \mathrm{~nm}$ size (Figure 5e). It is evident that the Ag terrace imaged in Figure 5c is not completed and formed by two layers involving a $0.7 \mathrm{~nm}$ height difference (Figure 5f). The growth of the $\mathrm{Ag}$ terrace takes place in two well-defined directions, namely, $30 \pm 10^{\circ}$ and $90 \pm 10^{\circ}$, with respect to the largest edge of the triangular crystallite. Furthermore, well-defined angles of $20 \pm 10^{\circ}, 40 \pm 10^{\circ}$, and 100 $\pm 10^{\circ}$ are formed along the edge of the large terrace depicted at the lower left-hand corner in Figure 5c.

The preceding morphological description, which covers different stages of growth of Ag crystallites, is consistent with a growth process involving the surface diffusion of $\mathrm{Ag}$ atoms from unstructured 3D nuclei to flat terraces. This mechanism can be easily supported by the high mobility of $\mathrm{Ag}$ surface atoms on $\mathrm{Ag}$ at the solid/solution interface at room temperature. ${ }^{16}$

Atomic resolution imaging was attempted on the top of $\mathrm{Ag}$ terrace domains and on flat areas surrounding Ag crystals, by using the current mode to minimize drift effects. Figure 6a corresponds to a STM image $\left(4.2 \times 4.2 \mathrm{~nm}^{2}\right)$ obtained on the flat area located about $20 \mathrm{~nm}$ from a $\mathrm{Ag}$ crystal edge. It shows a hexagonal array of atoms with $d=0.24 \pm 0.03 \mathrm{~nm}$ which, as already mentioned, corresponds to STM images of HOPG when only three of the six $\mathrm{C}$ atoms in the graphite lattice are observed. These results prove that at the early stages of $3 \mathrm{D} \mathrm{Ag}$ nuclei growth the $\mathrm{Ag}$ monolayer is still not completed. Therefore, under nonequilibrium Ag electrodeposition conditions $\left(\eta_{\mathrm{c}}=-0.025 \mathrm{~V}\right)$ the $3 \mathrm{D} \mathrm{Ag}$ phase appears to be more stable than the $2 \mathrm{D} \mathrm{Ag}$ monolayer. This conclusion is similar to that previously derived for the same system from in situ $\mathrm{STM}^{8}$ and $\mathrm{Ag}$ opd on Pt. ${ }^{17}$ It should be noted that the rearrangement of metal monolayers to form $3 \mathrm{D}$ metal nuclei and uncovered substrate domains in the overpotential region was firstly found for $\mathrm{Cu}$ electrodeposition on polycrystalline $\mathrm{Pt}{ }^{18}$ Hence, it appears that the $2 \mathrm{D} \Rightarrow 3 \mathrm{D}$ rearrangement plays an important role in the early stages of metal electrodeposition processes.
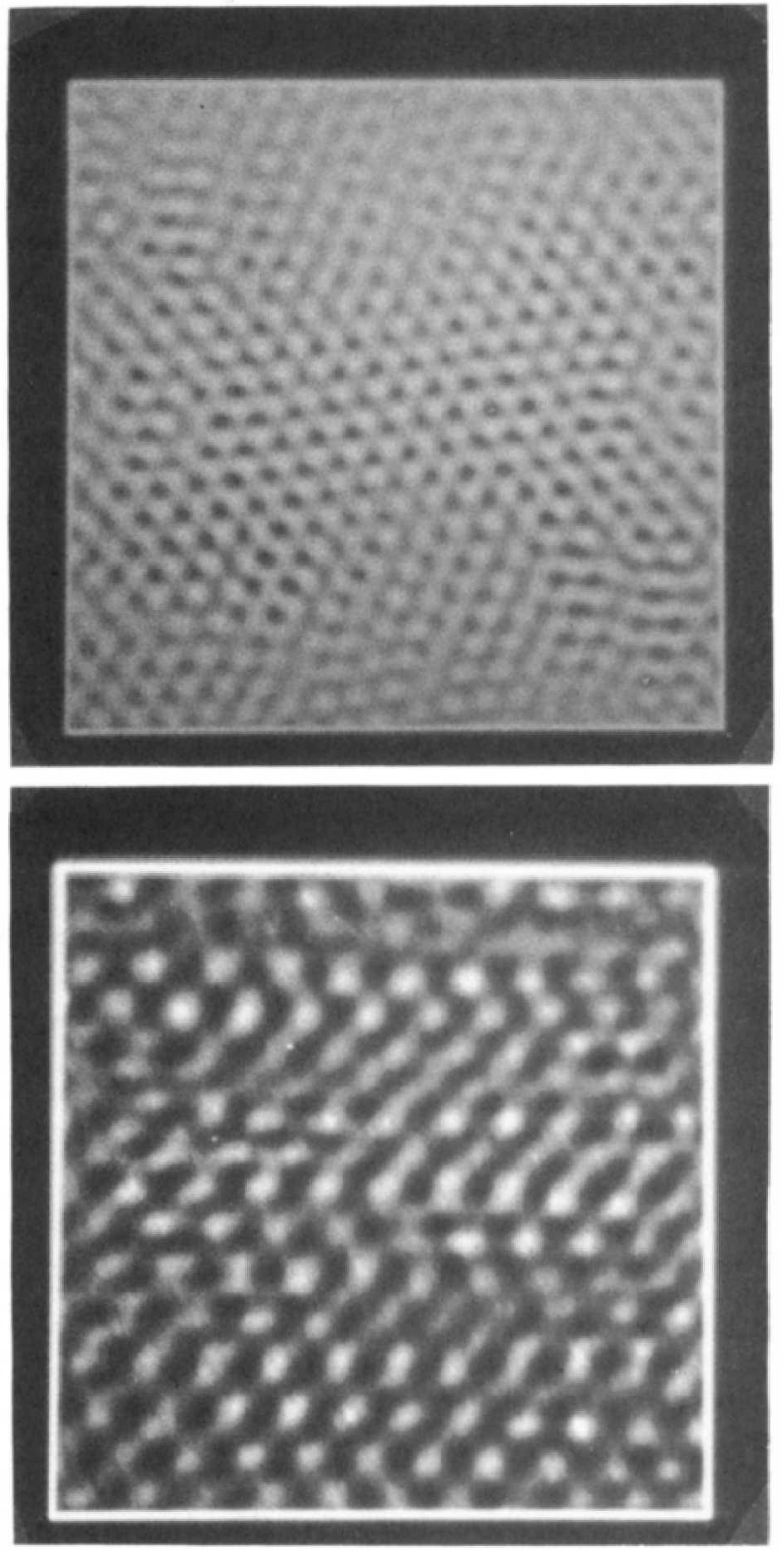

Figure 6. (a, top) STM image $\left(4.2 \times 4.2 \mathrm{~nm}^{2}\right)$ taken $20 \mathrm{~nm}$ from the Ag electrodeposit, $d=0.24 \pm 0.03 \mathrm{~nm}$; (b, bottom) STM image (3.1 $\times$ $3.1 \mathrm{~nm}^{2}$ ) of a flat geometric Ag crystal terrace, $d=0.29 \pm 0.03 \mathrm{~nm}$.

The atomic resolution STM image $\left(3.1 \times 3.1 \mathrm{~nm}^{2}\right)$ taken on a $\mathrm{Ag}$ terrace ( $2 \mathrm{~nm}$ height) (Figure $6 \mathrm{~b}$ ) displays also regular hexagonal lattice domains. This surface structure is in accordance with a $\mathrm{Ag}\{111\}$ crystallographic orientation. It should be noted that atomic resolution at metal surfaces is more difficult, ${ }^{19}$ and consequently, STM images are of lower quality as compared to those obtained on uncovered HOPG domains (Figure 6a), However, despite this drawback, the distance between nearest neighbor atoms along the $x$-direction derived from Figure $6 \mathrm{~b}$ results $d=0.29 \pm 0.03 \mathrm{~nm}$, which is very close to $d=0.288 \mathrm{~nm}$ in the $\mathrm{Ag}$ silver lattice. This result shows that, after a relatively short exposure time to the ambient atmosphere, the surface of the small and thin $\mathrm{Ag}$ crystallites grown on HOPG is not modified by oxygen species, a conclusion which is consistent with the AES results shown in Figure 2. The formation of a Ag surface oxide should involve a more prolonged exposure to air and it is characterized in the STM images by nearest-neighbor distances exceeding $d=0.288 \mathrm{~nm} .{ }^{20}$ This fact suggests that ex situ STM techniques can be applied to the investigation of the Ag/HOPG system provided that a prolonged contact with air is avoided.

Attention was paid to discover atomic features at flat domains located about $5 \mathrm{~nm}$ from the $\mathrm{Ag}$ crystal edges, i.e., at regions where one should expect the transition between uncovered and $\mathrm{Ag}$ - 

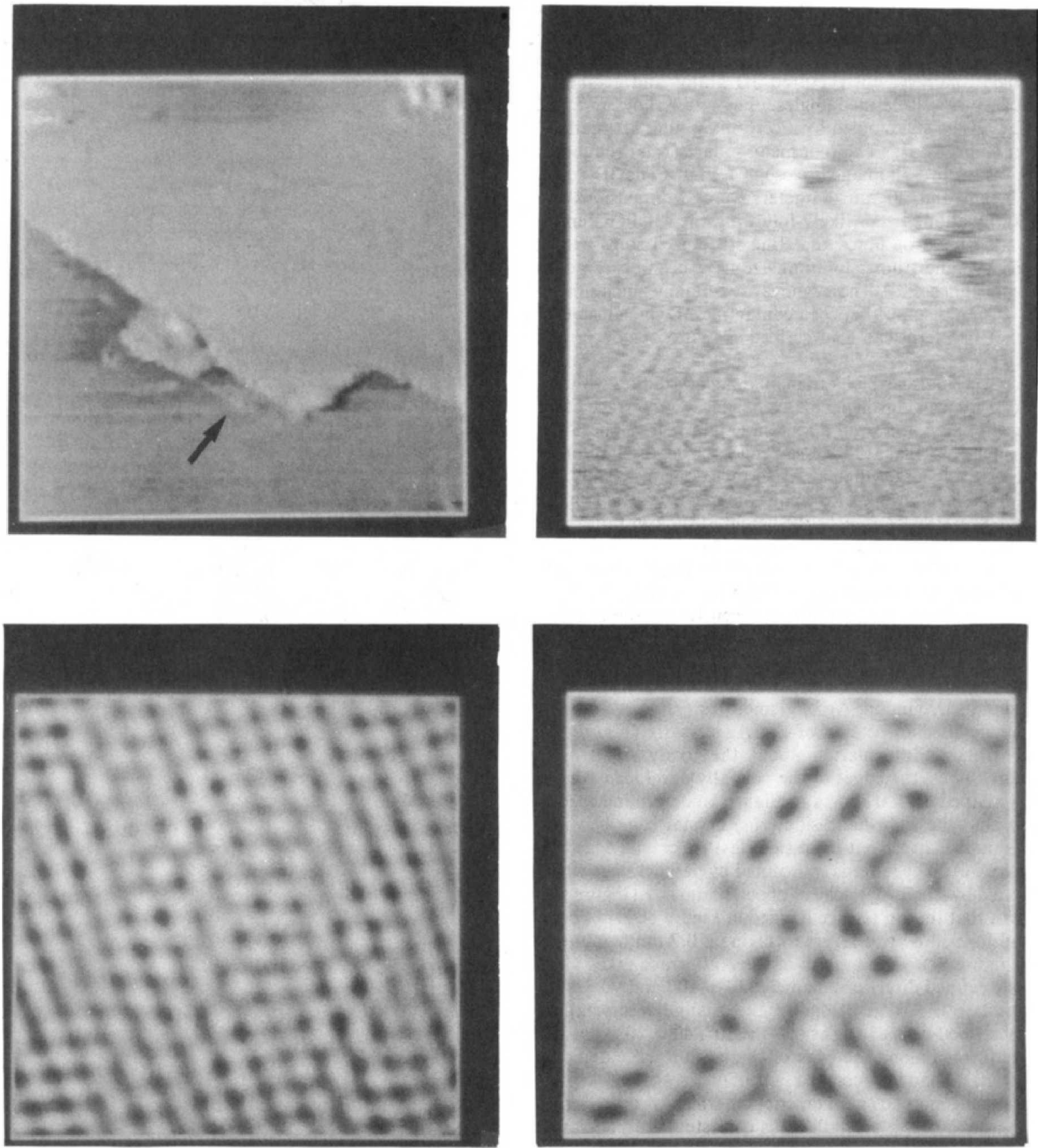

Figure 7. (a, top left) STM image $\left(82.4 \times 82.4 \mathrm{~nm}^{2}\right)$ top view, $\Delta h=1.8 \mathrm{~nm}$ ) of a large Ag terrace. A small Ag crystal at the step and a strip parallel to the step are observed. (b, top right) STM image $\left(7.3 \times 7.3 \mathrm{~nm}^{2}\right.$, raw data) obtained by zooming in the strip zone of part a. (c, bottom left) STM image $\left(3.3 \times 3.3 \mathrm{~nm}^{2}\right)$ of the rhs portion in part $\mathrm{b}, d=0.24 \pm 0.03 \mathrm{~nm}$. (d, bottom right) STM image $\left(2.3 \times 2.3 \mathrm{~nm} \mathbf{m}^{2}\right)$ of the lhs portion in part $\mathrm{b}$, $d=0.33 \pm 0.03 \mathrm{~nm}$

covered HOPG domains. A detailed inspection of a large terrace with a 0.8-nm step height involving the formation of a small $\mathrm{Ag}$ crystallite (Figure $7 \mathrm{a}$ ) reveals a very narrow strip ( $5 \mathrm{~nm}$ width, $0.3 \mathrm{~nm}$ height) (see arrow in Figure 7a) emerging from the small Ag crystal and running parallel to the step. A raw data image taken by zooming in on the strip zone (Figure 7b) exhibits three distinguishable regions. The first region which is seen in Figure $7 \mathrm{~b}$ (top rhs) corresponds to some irregularities (peaked structure). According to a recent interpretation, ${ }^{21}$ this structure could be related to small $\mathrm{Ag}$ clusters. The second region occupying the largest portion of the picture lies at the rhs of Figure 7b. It shows parallel rows of particles forming $70 \pm 10^{\circ}$ angles with respect to the horizontal direction taken as reference and some hexagonal cells with $d=0.24 \pm 0.02 \mathrm{~nm}$. A zoomed part of this region is displayed in Figure 7c. The third region, which is located at the lhs in Figure 7b (zoomed part showed in Figure 7d), displays a regular hexagonal lattice with $d=0.33 \pm 0.03 \mathrm{~nm}$. Although some distortion is evident, it can be seen that this lattice is slightly rotated by $10 \pm 10^{\circ}$ average with respect to the lattice structure shown at the rhs in Figure $7 \mathrm{~b}$.

The values of $d$ derived for the second and third regions are confirmed after standard Fourier transform. These results suggest, therefore, that the region involving the smallest periodicity corresponds to HOPG, whereas the region involving the greatest one can be assigned to an $\mathrm{Ag}$ overlayer at the submonolayer level, the nearest-neighbor distance of the latter being larger than that expected for the Ag lattice.

The structural parameters determined through the STM images for the first layer of $\mathrm{Ag}$ atoms on the substrate, namely $d=0.33$ $\pm 0.03 \mathrm{~nm}$ and the $10 \pm 10^{\circ}$ rotation, can be accounted for 

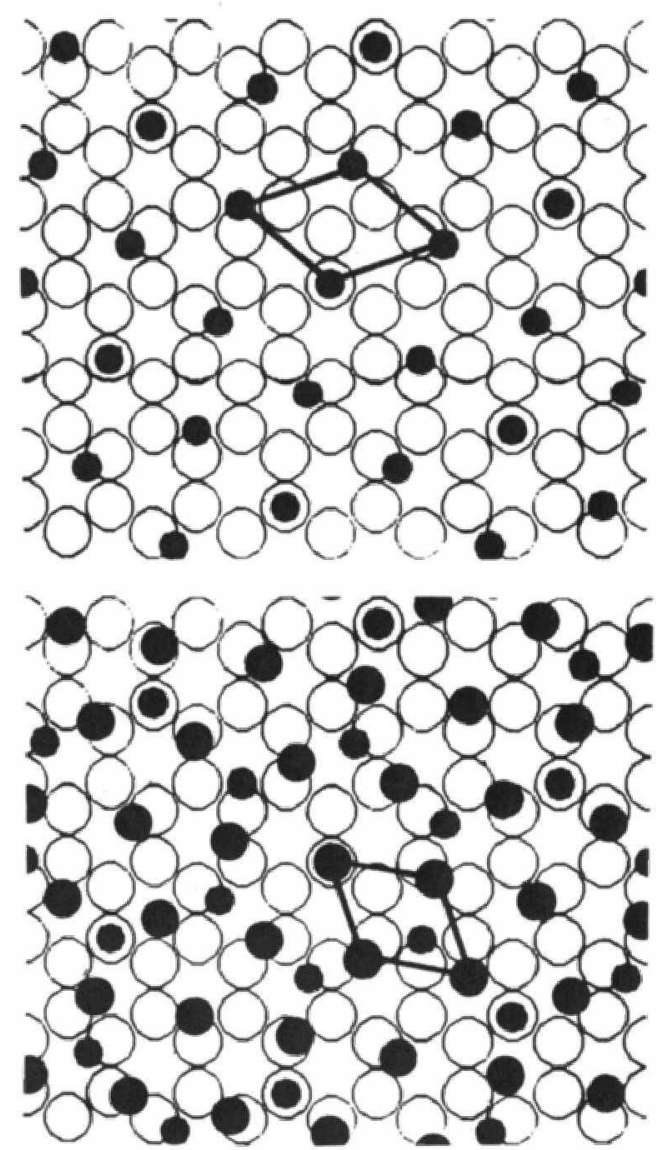

Figure 8. (a, top) Scheme of the $(\sqrt{ } 7 / 2 \times \sqrt{ } 7 / 2) R 19^{\circ}$ lattice structure for $\mathrm{Ag}$ on HOPG. Open circles represent the HOPG surface; full circles correspond to $A g$ atoms. (b, bottom) Scheme of the $(\sqrt{ } 3 / 2 \times \sqrt{ } 3 / 2)$ $R 30^{\circ}$ lattice structure of $\mathrm{Ag}$ on the $\mathrm{Ag}$ overlayer shown in part a. The open circles represent the HOPG lattice; small full circles stand for the first overlayer of $\mathrm{Ag}$ atoms; large full circles denote the second layer of Ag atoms. In both schemes the corresponding unit cells are drawn.

through a model consisting of a $(\sqrt{ } 7 / 2 \times \vee 7 / 2) R 19^{\circ}$ lattice structure (Figure 8a). This model also explains the $20^{\circ}$ angle formed by the edges of flat $\mathrm{Ag}$ terraces involving a corrugation which does not exceed $0.2 \mathrm{~nm}$ (Figure $5 \mathrm{c}$ ).

Otherwise, the growth of the $\mathrm{Ag}$ deposits on the $\mathrm{Ag}$-covered flat terraces would continue producing a $(\sqrt{ } 3 / 2 \times \sqrt{ } 3 / 2) R 30^{\circ}$ lattice structure (Figure $8 \mathrm{~b}$ ) leading to $d=0.282 \mathrm{~nm}$, a figure which is very close to $d=0.288 \mathrm{~nm}$ for the Ag lattice. Afterward the formation of the $\mathrm{Ag}$ phase would proceed with $d=0.288 \mathrm{~nm}$.

On the other hand, the appearance of an open Ag structure on HOPG at the submonolayer level (Figure 7b) would imply that repulsive interactions between $\mathrm{Ag}$ adatoms prevail at the initial stages of the Ag overlayer growth as concluded from recently reported in situ AFM and STM observations on $\mathrm{Cu}$ upd and $\mathrm{Ag}$ upd on Au\{111\}.22-24 Accordingly, the value of d depends markedly on the anion present in the electrolyte solution. 22,23 Thus, in $\mathrm{SO}_{4}{ }^{2-} / \mathrm{HSO}_{4}{ }^{-}$-containing solutions the $3 \times 3$ and $(\sqrt{ } 3 \times \sqrt{ } 3) R 30^{\circ}$ structures were observed for $\mathrm{Ag}$ upd and $\mathrm{Cu}$ upd on $\mathrm{Au}\{111\}$, respectively. The appearance of these structures has been attributed to the $\mathrm{SO}_{4}{ }^{2-} / \mathrm{HSO}_{4}{ }^{-}$adsorption atop the $\mathrm{Ag}$ atoms. ${ }^{22,23}$ However, as the value $d=0.33 \pm 0.03 \mathrm{~nm}$ is smaller than the $\mathrm{SO}_{4}{ }^{2-} / \mathrm{HSO}_{4}{ }^{-}$anion average diameter $(0.488 \mathrm{~nm})$, an explanation based on anion adsorption appears to be insufficient to account for the Ag overlayer structure. It should be noted that in the Ag opd potential range the existence of a residual positive charge at Ag electrodeposited atoms becomes unlikely. This fact can explain why the values of $d$ reported in this work are in good agreement with those obtained from STM imaging of $2 \mathrm{D}$ small $\mathrm{Ag}$ islands grown in vacuum on HOPG $(d=0.34 \pm 0.02 \mathrm{~nm}$ and $0.31 \pm 0.02$ $\mathrm{nm}){ }^{21}$

The structure of Ag electrodeposits grown at a high overpotential $\left(\eta_{\mathrm{c}}=0.05 \mathrm{~V}\right.$, arrow B Figure 2), i.e., at high electrode-

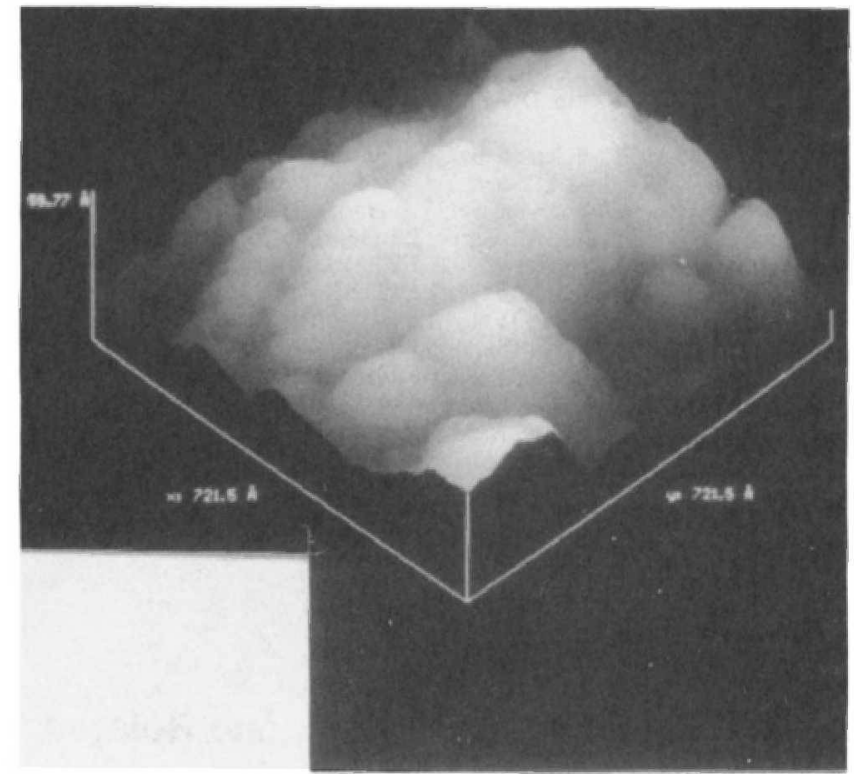

Figure 9. 3D STM image $\left(72.2 \times 72.2 \mathrm{~nm}^{2}, \Delta h=6 \mathrm{~nm}\right)$ of a $\mathrm{Ag}$ electrodeposit formed at $\eta_{\mathrm{c}}=-0.05 \mathrm{~V}$.

position rates (Figure 9), appears to be extremely disordered with 3D unstructured nuclei of about $10-20 \mathrm{~nm}$ average size. In contrast to results obtained at lower overpotentials, in this case no geometrical flat Ag crystals can be seen. These results confirm that the proper $\mathrm{Ag}$ deposition rate plays a relevant role in determining the growth mode of the $\mathrm{Ag}$ overlayer formed on a foreign substrate. ${ }^{25}$

Finally, it should be noted that after the anodic stripping of the Ag electrodeposits, the typical image of HOPG exhibiting flat surfaces limited by steps can be systematically recovered.

\section{Conclusions}

(i) Nucleation and 3D growth of Ag electrodeposits on HOPG initiates at surface defects, particularly at HOPG step edges.

(ii) HOPG defects are enhanced throughout decoration by 3D $\mathrm{Ag}$ nuclei. At flat HOPG domains the $\mathrm{Ag}$ nuclei are not observed.

(iii) Flat triangular Ag crystals with depressions at their centers are formed surrounding the Ag decorated HOPG steps. The structure of these crystals is consistent with a growth mechanism involving surface atom diffusion from $3 \mathrm{D} \mathrm{Ag}$ nuclei to $\mathrm{Ag}$ flat terraces. Atomic resolution on flat Ag terraces was achieved, the corresponding nearest-neighbor distance being $0.29 \pm 0.03 \mathrm{~nm}$.

(iv) Large uncovered $\mathrm{HOPG}$ areas and $\mathrm{Ag}$ submonolayers domains, compatible with a $(\sqrt{ } 7 / 2 \times \sqrt{ } 7 / 2) R 19^{\circ}$ structure, involving a nearest-neighbor distance greater than that expected for the $\mathrm{Ag}$ lattice have been distinguished. This indicates that the $\mathrm{Ag}$ monolayer becomes unstable under opd conditions leading to a $2 \mathrm{D} \Rightarrow 3 \mathrm{D}$ spontaneous change at the $\mathrm{Ag}$ overlayer.

(v) A lattice model is advanced which accounts for the transition between the nearest-neighbor distance values in going from the first $\mathrm{Ag}$ layer to the $\mathrm{Ag}$ phase.

(vi) Marked changes in the deposit topography are observed by increasing the overpotential for Ag electrodeposition.

Acknowledgment. This work was supported by CICYT (Spain) under project No. Mat89-0204. R.C.S. and A.J.A. thank CONICET (Argentina) for financial support.

\section{References and Notes}

(1) Budevski, E. B. In Comprehensive Treatise of Electrochemistry; Conway, B. E., Bockris, J. O'M., Yaeger, E., Khan, S. U. M., White, R. E., Eds.; Plenum Press: New York, 1983; Vol. 7, p 399.

(2) Green, M. P.; Hanson, K. J.; Carr, R.; Lindau, I. J. Electrochem. Soc. $1990,137,3493$.

(3) Magnussen, O. M.; Hotlos, J.; Nichols, R. J.; Kolb, D. M.; Behm, R. J. Phys. Rev. Lett. 1990, 64, 2929.

(4) Yau, S. L.; Vitus, C. M.; Schard, B. C." J. Am. Chem. Soc. 1990, 1/2, 3677. 
(5) Magnussen, O. M.; Hotlos, J.; Beitel, G.; Kolb, D. M.; Behm, R. J. J. Vac. Sci. Technol. B 1991, 9, 969.

(6) Szklarczyk, M.; Bockris, J. O.'M. J. Electrochem. Soc. 1990, 137, 452

(7) Nichols, R. J.; Kolb, D. M.; Behm, R. J. J. Electroanal. Chem. 1991, $313,109$.

(8) Sonnenfeld, R.: Schardt, B. C. Appl. Phys. Lett. 1986, 49, 1172

(9) Itaya, K.; Tomita, E. Surf. Sci. 1988, 201, L507.

(10) Robinson, R. S. J. Vac. Sci. Technol. A 1990, 8 , 511.

(11) Hernández-Creus, A.; Carro, P.; Gonzälez, S.; Salvarezza, R. C.; Arvia, A. J. Electrochim. Acta 1992, 37, 2215.

(12) Binning, G.; Fuchs, H.; Gerber, Ch.; Rohrer, H.; Stoll, E.; Tosatti, E., Europhys. Lett. 1986, 1, 31.

(13) Ganz, E.; Sattler, K.; Clarke, J. J. Vac. Sci. Technol. A 1988, 6, 419.

(14) Salmeron, M.; Beebe, T.; Odriozola, J.; Wilson, T.; Ogletree, D. F.; Siekhaus, W. J. Vac. Sci. Technol. A 1990, 8,635.

(15) Lorenz, W. J.; Gassa, L. M.; Schmidt, U.; Obretenov, W.; Staikov, G.; Bostanov, V.; Budevski; E. Electrochim. Acta 1992, 37, 2173.

(16) Salvarezza, R. C.; Vara, J. M.; Arvia, A. J. Langmuir, in press.
(17) Alonzo, D.; Scharifker, B. J. Electroanal. Chem. 1989, 274, 167. (18) Margheritis, D.; Salvarezza, R. C.; Giordano, M. C.; Arvia, A. J. J. Electroanal. Chem. 1987, 229, 327.

(19) Behm, R. J. Scanning Tunneling Microscopy and Related Methods; Behm, R. J., Garcia, N., Rohrer, H., Eds.; NATO ASI Series 184; Plenum: New York, 1989, p 173.

(20) Obretenov, W.; Höpfner, M.; Lorenz, W. J.; Budevski, E.; Staikov, G.; Siegenthaler, H. Surf. Sci. 1992, 27I, 191.

(21) Ganz, E.; Sattler, K.; Clarke, J. Surf. Sci. 1989, 219, 33.

(22) Manne, S.; Hansma, P. K.; Massie, J.; Elings, V. B.; Gewirth, A. A. Science 1991, 251, 183

(23) Chen, Chun-hsien; Vesecky, S.; Gewirth, A. J. Am. Chem. Soc. 1992, 114,451 . 275 .

24) Hachiya, T.; Honbo, H.; Itaya, K. J. Electroanal. Chem. 1991, 315 ,

(25) Vâzquez, L.; Bartolome, A.; Barô, A. M.; Alonso, C.; Salvarezza, R. C.; Arvia, A. J. Surf. Sci. 1989, $215,171$.

\title{
Modeling of AlPO,-8, VPI-5, and Related Structures
}

\author{
A. J. M. de Man, R. A. van Santen, ${ }^{*}$ \\ Schuit Institute of Catalysis, Eindhoven University of Technology, P.O. Box 513, 5600 MB Eindhoven, \\ The Netherlands
}

\author{
and E. T. C. Vogt
}

AKZO Chemicals BV, Research Centre Amsterdam, P.O. Box 26223, 1002 GE Amsterdam, The Netherlands (Received: October 14, 1991; In Final Form: June 25, 1992)

\begin{abstract}
The structure and infrared spectrum of $\mathrm{AlPO}_{4}-8$, the 18-ring aluminophosphate VPI-5, and related structures are simulated using atomistic potentials and a generalized valence force field. The various topologies theoretically possible for the VPI-5 structure indicate that hexagonal prisms and cubes in the structure increase its lattice energy, thus decreasing the plausibility of the structure. This is not the only energy-determining feature; the relative orientation of neighboring tetrahedra also has an effect. The calculated differences in lattice energy between the 14-ring structure $\mathrm{AlPO}_{4}-8$, the 18-ring structure VPI-5, and a hypothetical 24-ring structure are mainly due to density differences; no direct effect of the ring size on the lattice energy has been observed. Both VPI-5 and $\mathrm{AlPO}_{4}-8$ show a shift of layers when their lattice energy is minimized by optimizing the crystallographic coordinates and unit cell parameters. The hypothetical 24-ring structure does not show such a shift. This is probably due to the flexibility of the 24-rings that can completely accommodate strains in the initial structure. This is also indicated by the large loss of symmetry of the structure. The simulated infrared spectra reproduce essential differences between the experimental spectra of $\mathrm{AlPO}_{4}-8$ and VPI-5. The highest frequency modes, however, are calculated to be too high. Spectra calculated with the structures obtained by lattice energy minimization agree better with experiment than those calculated with experimental structures. This can be explained by the presence of more physically acceptable angles in the relaxed structures compared with the experimental structures. The calculated spectrum of the hypothetical 24-ring structure is clearly distinguishable from that of VPI-5.
\end{abstract}

\section{Introduction}

One of the most spectacular zeolitic structures known today is VPI-5. This $\mathrm{AlPO}_{4}$ material has pores with rings existing of 18 tetrahedra (called 18-rings), thus causing a pore diameter that is greater than $12 \AA$. The first reports of this structure, ${ }^{1,2}$ in 1988 , received much interest because of the need for large-micropore, well-defined catalytic materials. The XRD pattern of VPI-5 is very similar ${ }^{3}$ to that of the SAPO structure MCM-9, which was patented in 1987.4 Analogies between VPI-5 and AlPO -8 , which was first made in $1982,{ }^{5}$ have been noted ${ }^{3}$ as well. At that time, it was suggested that $\mathrm{MCM}-9$ and $\mathrm{AlPO}_{4}-8$ also contain 18 membered rings. MCM-9 is a mixture of Si-VPI-5 and the 10-ring-containing structure SAPO-11, $3,6 \mathrm{AlPO}_{4}-8$ has also been suggested to consist of 18-membered rings in layers that are shifted relative to each other ${ }^{7}$ (Figure 1), thus explaining its lower adsorption capacity. ${ }^{3}$ Although by now the sizes of the rings in $\mathrm{AlPO}_{4}-8$ and VPI-5 are beyond discussion, the details of their structures are still uncertain. Experimental structure refinements have shown that $\mathrm{AlPO}_{4}-8$ actually contains 14 -rings, ${ }^{8}$ as was suggested for an early DLS structure. ${ }^{9}$ The observed transformation ${ }^{10}$ of VPI-5 to $\mathrm{AlPO}_{4}-8$, be it reversible or not, also indicates a close relation between the two structures. Vinje et al. ${ }^{11}$ observed that rather large conversions of VPI-5 to $\mathrm{AlPO}_{4}-8$ result in minor changes in X-ray diffractograms, even though the pure VPI-5 and $\mathrm{AlPO}_{4}-8$ structures each show some unique features. They hypothesize from powder XRD and HR-TEM the general existence of unrearranged VPI-5 in AlPO ${ }_{4}^{-8}$, which of course obscures the structure determination of the latter. This apparently contradicts the conclusions of Davis et al. ${ }^{3}$ based on a combination of argon adsorption isotherms and powder XRD experiments that $\mathrm{AlPO}_{4}-8$ does not contain extra large pores. The experimental data can also be explained by pore blocking. Another impurity often hindering the structure refinement of VPI-5 and $\mathrm{AlPO}_{4}-8$ is the $\mathrm{AlPO}_{4}$ hydrate $\mathrm{H} 3{ }^{9,12,13}$ Theoretically, modeling of $\mathrm{AlPO}_{4}$ structures can help to solve these problems.

The VPI-5 topology is part of an infinite range of hexagonal $(4 ; 2)$ networks with increasing pore size designated $81,81(1)$, and $81(2)^{14,15}$ (Figure 2). Net 81 corresponds to the 12-ring structure 